\title{
"PENGARUH PENERAPAN PEMBELAJARANVALUE CLARIFICATION TECHNIQUE(VCT) TERHADAP SIKAP DEMOKRASI SISWA KELAS X AK 2 SMK MUHAMMADIYAH 1 GENTENG SEMESTER GANJIL TAHUN PELAJARAN 2017/2018."
}

\author{
Moh. Andris Solahudin ${ }^{1}$ Yuli kartika effendi ${ }^{2}$ \\ SMK MUHAMMADIYAH 1 GENTENG \\ Email: andresmohammad06@gmail.com Yulikartikaefendi@gmail.com
}

\begin{abstract}
ABSTRAK
Penelitian ini bertujuan untuk mengetahui peningkatan kemampuan siswa dalam memahami sistem pemerintahan Indonesia pada mata pelajaran PKn melalui model pembelajaran student teams achievement devision (VCT) dan pembelajaran problem solving kelas X Transmisi SMK Muhammadiyah 1 Genteng.

Penelitian ini merupakan penelitian kuantitatif. Subjek penelitian ini adalah siswa kelas $X$ Transmisi Semester ganjil Tahun akademik 2017/2018 dengan jumlah 30 siswa. Teknik pengumpulan data pada penelitian ini menggunakan observasi, interview, tes ketuntasan belajar, dan dokumentasi.Teknik analisis data yang digunakan adalah analisis deskriptif kualitatif.Hasil penelitian menunjukkan bahwa penerapan model pembelajaran) pada mata pelajaran PKn dari hasil perhitungan statistic dapat disimpulkan bahwa $F_{\text {reg }}=30,448 \geq F_{\text {tabel }} 5 \%=3,34$. Dengan demikian dapat dikatakan bahwa "Ada Pengaruh Model Pembelajaran Student Teams Achievement Devision (STAD) terhadap Peningkatan Kemampuan Siswa dalam Memahami Sistem Pemerintah Indonesia dalam Pelajaran PKn Kelas X Semester Ganjil SMK Telekomunikasi Genteng 2017/2018”
\end{abstract}

Kata kunci : Student TeamsAchievement Devision (STAD); problem solving; kemampuansiswadalammemahamimateri; $P K n$.

\section{PENDAHULUAN}

Pendidikan

kewarganegaraan merupakan wahana untuk mengembangkan dan melestarikan nilai luhur dan moral yang berakar pada budaya bangsa Indonesia yang diharapkan dapat diwujudkan dalam perilaku kehidupan sehari-hari siswa, baik sebagai individu, sebagai suatu kelompok, maupun sebagai anggota masyarakat, warga negara, dan makhluk ciptaan Tuhan Yang Maha Esa.

Perilaku-prilaku yang demokratis dan berkeadilan serta tidak diskriminatif dengan menjunjung tinggi hak asasi manusia, nilai keagamaan, nilai kultural, dan kemajemukan bangsa dengan satu kesatuan yang sistemik dengan sistem terbuka dan multimakna yang dimaksud tercantum di dalam penjelasan Undang-undang tentang sistem Pendidikan Nasional No 20 Tahun 2003 yaitu, Pendidikan kewarganegaraan merupakan usaha untuk membekali siswa dengan pengetahuan dan kemampuan dasar berkenaan dengan hubungan antar Negara dengan Negara serta pendidikan bela Negara-negara agar menjadi warga Negara yang dapat diandalkan oleh bangsa dan negara. Sebagai suatu mata pelajaran yang ada dalam kurikulum sekolah, PPKn memiliki misi, di antaranya adalah sebagai pendidikan dasar untuk mendidik warga negara agar mampu berfikir kritis dan kreatif, mengkritisi, mengembangkan pikiran.Untuk itu siswa perlu memiliki kemampuan belajar tepat, menyatakan dan mengeluarkan pendapat, mengenal dan melakukan telaah terhadap permasalahan yang timbul di lingkungannya agar tercapai perilaku yang diharapkan.

Pelaksanaan pembelajaran PPKn di sekolah kenyataannya banyak ditemukan berbagai kendala sehingga tujuan pembelajaran yang diharapkan tidak tercapai dengan baik. Salah satu kendala itu antara lain tidak kurangnya pemahaman siswa 
dalam materi, kurangnya keaktifan siswa dalam pendapat.

Berdasarkan pengamatan observasi masalah yang dilakukan peneliti di SMK Telekomunikasi Genteng terhadap masalah yang timbul berkaitan degan pembelajaran pada Kelas X, keaktifan siswa masih kurang karena kurangnya pemahaman siswa dalam mata pelajaran tersebut, hal ini tercemin dari interaksi guru dengan siswa yang belum maksimal karena guru yang belum maksimal karena guru dominan menggunakan model pembelajaran konvensional yang kurang menstimulus siswa untuk berpendapat di ruangan kelas, dimana pembelajaran konvensional meminta siswa untuk belajar sendiri tanpa bimbingan dari guru, ketika ada bimbingan pun siswa langsung diminta untuk menghafalkan materi sistem pemerintah Indonesia, padahal mata pelajaran PPKn merupakan belajar konsep dan bermakna, bukan pembelajaran konvensional (hafalan). Siswa pada proses pembelajaran menjadikan guru sebagai tokoh sentral, artinya sumber belajar hanya terdapat pada ceramah guru, guru dengan meodel konvensional memberikan doktrin mata pelajaran dengan sedikit variasi belajar, terkadang dalam pembelajaran guru menggunakan model pembelajaran kelompok maupun individu, hal ini memberikan efek kurangnya variasi pembelajaran sehingga siswa menjadi malas untuk memperhatikan pembelajaran.

Dari masalah yang telah disebutkan diatas maka akibat yang tampak yaitu pada hasil belajar siswa kelas $X$ SMK Telekomunikasi Genteng yang kurang memuaskan dan kurang dari KKM. Dari permasalahan yang timbul di SMK Telekomunikasi Genteng maka perlu solusi yang sesuai dengan prinsip pembelajaran aktif, guru sebagai fasilitator yang memang kunci keberhasilan tujuan pembelajaran. Berdasarkan masalah yang ada pada kelas $\mathrm{X}$ SMK Telekomunikasi, maka guru hendaknya memilih pembelajaran yang tepat, memberikan penyajian mata pelajaran yang menarik, membuat siswa aktif dalam suasana kelompok yang berjuan adanya interaksi sosial antara guru dengan siswa, siswa dengan guru dan siswa dengan guru, sehingga pembelajaran tidak berpusat pada guru, namun berpusat pada siswa.

Untuk itu model pembelajaran yang disarankan oleh peneliti yaitu menggunakan model pembelajaran Student Teams Achievement Devision (STAD) dan pembelajaranProblem Solving (pemecahan masalah) dimana kedua model pembelajaran diatas merupakan model pembelajaran yang bertujuan mendapatkan kesempatan untuk memberikan konstribusi kepada siswa dalam memahami dan menemukan pemecahan masalah suatu materi serta mengkonstribusi siswa memberikan pendapat mereka dan mendengarkan pandangan serta pemikiran anggota lain, digunakan untuk mengajarkan keterampilan sosial, serta untuk menghindari siswa mendominasi pembicaraan atau siswa diam sama sekali. Biasanya siswa malu utnuk berpendapat sehingga pemahaman siswa menjadi kurang, jadi untuk membuat siswa menjadi berani berbicara perlu memberikan kesempatan atau peluang kepada siswa.

Berdasarkan persoalan diatas peneliti ingin meneliti akan "pengaruh model pembelajaran Student Teams Achievement Devision(STAD) dan pembelajaran problem solving terhadap peningkatan kemampuan siswa dalam memahami sistem pemerintahan indonesia dalam pelajaran PKn kelas X Semester Ganjil SMK Telekomunikasi Genteng 2017/2018.

(2) Rumusan Masalah

Masalah Mayor

Adakah pengaruh model pembelajaran

STAD dan Problem Solving dalam meningkatkan kemampuan pemahaman siswa dalam materi sistem pemerintahan Indonesia pelajaran PKn kelas X Semester Ganjil SMK Telekomunikasi Genteng 2017/2018?

Masalah Minor

(a)Adakah pengaruh model pembelajaran students teams achievement devision (STAD) di kelas dalam meningkatkan kemampuan pemahaman siswa materi sistem pemerintahan Indonesia kelas $\mathrm{X}$ 
Semester Ganjil SMK Telekomunikasi Genteng 2017/2018?

(b)Adakah pengaruh model pembelajaran Problem Solvingdi kelas dalam meningkatkan kemampuan pemahaman siswa materi sistem pemerintahan Indonesia kelas X Semester Ganjil SMK Telekomunikasi Genteng 2017/2018?

\section{METODE PENELITIAN}

Pada Penelitian ini peneliti menggunakan penelitian kuantitatif ini dilakukan di SMK Telekomunikasi Genteng yang berlokasi di Jalan Mliwis No.29 Sawahan Genteng Banyuwangi. Penentuan tempat penelitian menggunakan metode purposive area yaitu tempat penelitian ditentukan dengan sengaja oleh peneliti. Pemilihan tempat didasarkan adanya permasalahan yang dihadapi guru dalam meningkatkan keaktifan dan ketuntasan belajar siswa. Selain itu, pertimbangan lainnya karena adanya kesediaan dari kepala sekolah SMK Telekomunikasi Genteng untuk dijadikan tempat penelitian, serta disekolah tersebut belum pernah dilakukan penelitian dengan menerapkan model pembelajaran STAD dan Problem solving khususnya pada pelajaran PKn.

Penelitian akan dilaksanakan di SMK Telekomunikasi Genteng semester ganjil tahun ajaran2017/2018. Penelitian ini dilaksanakan bersamaan dengan pelaksanaan kegiatan pembelajaran sehingga tidak mengganggu proses pembelajaran yang sedang berlangsung. Lama pelaksanaan tindakan yaitu sesuai alokasi waktu menurut silabus mata pelajaran PKn kompetensi dasar membuat dan membukukan jurnal penyesuaian SMK Telekomunikasi Genteng tahun ajaran 2017/2018 dan kebijakan kepala sekolah SMK Telekomunikasi Genteng. Alokasi waktu yang ditetapkan yaitu 2 x40 menit.

Sedangkan penentuan responden yang digunakan adalah Populasi atau pengambilan contoh secara langsung tanpa acak. Subjek penelitian atau responden adalah pihak-pihak yang dijadikan sebagai sampel dalam sebuah penelitian. Responden adalah orang-orang yang dijadikan sebagai respon atau memberikan jawaban terhadap penelitian yang dilakukan dan populasi yang digunakan peneliti adalah SMK Telekomunikasi Genteng.

Dalam penelitian ini data diperoleh oleh peneliti dengan menggunakan beberapa teknik pengumpulan data.

Adapun teknik pengumpulan data yang digunakan adalah menggunakan angket tertutup karena dalam angket terutup sudah disusun jawabannya terlebih dahulu untuk membantu responden menjawab dengan cepat dan juga memudahkan peneliti dalam melakukan analisis data terhadap seluruh angket yang telah terkumpul. Kuesioner atau angket yang digunakan dalam penelitian ini adalah jenis kuesioner atau angket langsung yang tertutup karena responden hanya tinggal memberikan tanda pada salah satu jawaban yang dianggap benar.

Disamping tes hasil belajar digunakan sebagai salah satu instrumen untuk mengumpulkan data dalam pengukuran hasil tindakan penelitian. Tes yang dikembangkan oleh peneliti berupa pretest dan posttest yaitu untuk mengukur hasil siswa dalam mengemukakan pendapat. Posttest digunakan untuk mengetahui hasil siswa berpendapat setelah diberikan tindakan.

Dalam mengumpulkan data tersebut peneliti juga menggunakan tehnik wawancara. Wawancara yang dilakukan dalampenelitian ini adalah wawancara terstruktur, yaitu wawancara yang dilakukan dengan mengajukan pertanyaan-pertanyaan kepada responden yang telah disusun terlebih dahulu.

Sedangkan dokumentasi digunakan untuk peneliti untuk memperoleh data-data berupa daftar nilai awal, foto-foto yang memberikan gambaran secara konkret mengenai aktivitas siswa selama mengikuti proses pembelajaran, serta data dan dokumen-dokumen lain seperti data siswa dan struktur organisasi.

Dalam metode analisis data peneliti menggunakan analisis regresi ganda, analisis regresi ganda merupakan analisis statistik yang memanfaatkan hubungan antara dua 
atau lebih perubahan kuantitatif sehingga salah satu perubahan bisa diramalkan dari perubahan lainnya. Misalnya jika kita tahu hubungan antara kemampuan awal siswa dan prestasi belajar siswanya pada tahun pertama di Sekolah Menengah Kejuruan (SMK). Maka kita dapat meramal.Analisis regresi mempunyai tiga kegunaan utama (1) deskripsi, (2) kontrol atau kendali, dan (3) peramalan.

$$
\mathrm{Y}=\mathrm{a}+\mathrm{b}_{1} \mathrm{X}_{1}+\mathrm{b}_{2} \mathrm{X}_{2}
$$

Keterangan:

$\mathrm{Y}=$ Variable tak bebas

$\mathrm{X}_{1}=$ Variable bebas ke 1

$\mathrm{X}_{2}=$ Variable bebas ke 2

$\mathrm{a}=$ Konstanta

$\mathrm{b}_{1}=$ Kemiringan ke 1

$\mathrm{b}_{2}=$ Kemiringan ke 2

\section{HASIL DAN PEMBAHASAN}

Dalam analisa data penhujian hipotesa menggunakan analisa statistik dengan rumus regresi linier berganda dua prediktor dan menguji hipotesa yang diajukan diadakan test signifikan dengan persamaan regresi menggunakan $F_{\text {reg }}$.

Dalam menganalisa data dan pengujian hipotesa Minor I yaitu tentang kemampuan siswa dalam memahami susunan pemerintahan dalam pelajaran PKn (Y) dengan penerapan model pembelajaran student teams achievement devision (STAD) $\left(\mathrm{X}_{1}\right)$. Hipotesa kerja yang diajukan berbunyi " Ada pengaruh penerapan model pembelajaran student teams achievement devision (STAD) terhadap peningkatan kemampuan siswa dalam memahami sistem pemerintahan Indonesia dalam pelajaran PKn kelas $X$ semester ganjil SMK Telekomunikasi Genteng 2017/2018.

Dari hasil perhitungan diatas, dapat disimpulkan bahwa $F_{\text {reg }}=30,448 \geq F_{\text {tabel }} 5 \%$ $=3,34$. Dengan demikian dapat dikatakan bahwa "Ada Pengaruh Penerapan Model Pembelajaran Student Teams Achievement Devision (STAD) terhadap Peningkatan Kemampuan Siswa dalam Memahami Materi Sistem Pemerintahan Indonesia dalam Pelajaran PKn Kelas X Semester
Ganjil SMK Telekomunikasi Genteng 2017/2018".

Dalam menganalisa data dan pengujian hipotesa Minor II yaitu tentang kemampuan siswa dalam memahami materi sistem pemerintahan Indonesia dalam peajaran PKn (Y) dengan penerapan model pembelajaran Problem Solving $\left(\mathrm{X}_{2}\right)$. Hipotesa kerja yang diajukan berbunyi "Ada Pengaruh Penerapan Model Pembelajaran Problem Solving terhadap Peningkatan Kemampuan Siswa dalam Memahami Materi Sistem Pemerintahan Indonesia dalam Pelajaran PKn Kelas X Semester Ganjil SMK Telekomunikasi Genteng 2017/2018".

Dari hasil perhitungan diatas, dapat disimpulkan bahwa $\mathrm{F}_{\text {reg }}=0,077 \leq \mathrm{F}_{\text {tabel }} 5 \%$ $=3,34$. Dengan demikian dapat dikatakan bahwa "Tidak Ada Pengaruh Penerapan Model Pembelajaran Problem Solving tehadap Peningkatan Kemampuan Siswa dalam Memahami Materi Sistem Pemerintahan Indonesia dalam Pelajaran PKn Kelas X Semester Ganjil SMK Telekomunikasi Genteng 2017/2018".

Dalam menganalisa data dan pengujian hipotesa Mayor yaitu tentang kemampuan siswa dalam memahami materi sistem pemerintahan Indonesia pelajaran PKn (Y) dengan penerapan model pembelajaran student teams achievement devision (STAD) $\left(\mathrm{X}_{1}\right)$ dan penerapan model pembelajaran problem solving $\left(\mathrm{X}_{2}\right)$. Hipotesa kerja yang diajukan berbunyi “ Ada Pengaruh Model Pembelajaran Student Teams Achievement Devision (STAD) dan Pembelajaran Problem Solvingterhadap Peningkatan Kemampuan Siswa dalam Memahami Sistem Pemerintah Indonesia dalam Pelajaran Pkn Kelas X Semester Ganjil SMK Telekomunikasi Genteng 2017/2018.

Dari hasil perhitungan diatas, dapat disimpulkan bahwa $\mathrm{F}_{\text {reg }}=76,400 \geq \mathrm{F}_{\text {tabel }} 5 \%$ $=3,35$. Dengan demikian dapat dikatakan bahwa "Ada PengaruhModel Pembelajaran Student Teams Achievement Devision (STAD) dan Pembelajaran Problem Solving terhadap Peningkatan Kemampuan Siswa 
dalam Memahami Sistem Pemerintah Indonesia Dalam Pelajaran Pkn Kelas X Semester Ganjil SMK Telekomunikasi Genteng 2017/2018".

Menghitung Taraf Korelasi

$$
\begin{aligned}
\mathrm{R}^{2}=\frac{J K_{r e g}}{\Sigma Y^{2}} & =\frac{594,472}{812,367} \\
& =0,731
\end{aligned}
$$

Menghitung Sumbangan Relatif (SR)

$$
\begin{aligned}
\mathrm{SR}_{Y} & =\frac{b_{1 . \Sigma \times 1 Y}}{J K_{\text {reg }}} \times 100 \% \\
& =\frac{-1,071 \cdot(-550,7)}{594,472} \times 100 \% \\
& =\frac{589,799}{594,472} \times 100 \% \\
& =99,213 \%
\end{aligned}
$$

Menghitung Sumbangan Relatif (SR)

$$
\begin{aligned}
\mathrm{SR}_{Y} & =\frac{b_{1 . \Sigma X 1 Y}}{J K_{\text {reg }}} \times 100 \% \\
& =\frac{-1,071 \cdot(-550,7)}{594,472} \times 100 \% \\
& =\frac{589,799}{594,472} \times 100 \% \\
& =99,213 \%
\end{aligned}
$$

Menghitung Sumbangan Efektif (SE)

SEy $=$ SRy.R $\mathbf{R}^{2}=99,213 \% \quad \cdot 0,731=$ $72,524 \%$

Dari perhitungan diatas diketahui bahwa mempunyai sumbangan efektif sebesar $72,524 \%$ kemampuan siswa dalam memahami sistem pemerintah Indonesia dalam pelajaran Pkn (Y). Dengan demikian Pengaruh penerapan model pembelajaran student teams achievement devision (STAD) merupakan prediktor yang lebih dominan dalam memprediksi peningkatan kemampuan siswa dalam memahami sistem pemerintah Indonesia dalam pelajaran Pkn materi sistem pemerintahan.

Hasil Rekapitulasi Analisa Data Sumbangan Efektif

\begin{tabular}{|c|c|c|c|c|}
\hline \multirow{2}{*}{$\begin{array}{c}\text { Hipote } \\
\text { sa }\end{array}$} & \multirow{2}{*}{$\begin{array}{c}\text { Hasil } \\
\text { Freg }_{\text {reg }}\end{array}$} & $\begin{array}{c}\text { DF }\left(\mathrm{df}_{1}\right. \\
\left.\text { dan } \mathrm{df}_{2}\right)\end{array}$ & $5 \%$ & Analisa \\
\hline Minor I & $\begin{array}{c}30,44 \\
8\end{array}$ & $\begin{array}{c}1 \text { dan } \\
28\end{array}$ & 3,34 & Signifikan \\
\hline $\begin{array}{c}\text { Minor } \\
\text { II }\end{array}$ & 0,077 & $\begin{array}{c}1 \text { dan } \\
28\end{array}$ & 3,34 & $\begin{array}{c}\text { Tidak } \\
\text { Signifikan }\end{array}$ \\
\hline Mayor & $\begin{array}{c}76,40 \\
0\end{array}$ & $\begin{array}{c}2 \text { dan } \\
27\end{array}$ & 3,35 & Signifikan \\
\hline
\end{tabular}

Hasil Perhitungan Sumbangan Relatif (SR) dan Sumbangan Efektif (SE)

\begin{tabular}{|c|c|c|}
\hline Variabel & SR & SE \\
\hline Y & $99,213 \%$ & $72,524 \%$ \\
\hline
\end{tabular}

Dari hasil perhitungan diatas, dapat disimpulkan bahwa $\mathrm{F}_{\text {reg }}=30,448 \geq \mathrm{F}_{\text {tabel }} 5 \%$ $=3,34$. Dengan demikian hipotesa nihil $(\mathrm{Ho}$ yang diajukan ditolak) dan Hipotesa Kerja (Ha) diterima karena $\mathrm{F}_{\text {reg }}$ lebih besar dari $\mathrm{F}_{\text {tabel. }}$

Sehingga hipotesa berbunyi "Ada Pengaruh Model Pembelajaran Student Teams Achievement Devision (STAD) terhadap Peningkatan Kemampuan Siswa dalam Memahami Sistem Pemerintah Indonesia dalam Pelajaran PKn Kelas X Semester Ganjil SMK Telekomunikasi Genteng 2017/2018". Interprestasi hipotesa kerja minor I dapat dilihat dari perhitungan tabel diatas yang hasilnya adalah 30,448.

Dari hasil perhitungan diatas, hipotesa minor II dapat disimpulkan bahwa $\mathrm{F}_{\text {reg }}=0,077 \leq \mathrm{F}_{\text {tabel }} 5 \%=3,34$. Dengan demikian hipotesa nihil (Ho yang diajukan diterima) dan Hipotesa Kerja (Ha) ditolak karena $F_{\text {reg }}$ lebih kecil dari $F_{\text {tabel. }}$

Sehingga hipotesa berbunyi "Tidak Ada PengaruhPembelajaran Problem Solving terhadap Peningkatan Kemampuan Siswa dalam Memahami Sistem Pemerintah Indonesia dalam Pelajaran PKn Kelas X Semester Ganjil SMK Telekomunikasi Genteng 2017/2018". Interprestasi hipotesa kerja minor II dapat dilihat dari perhitungan tabel diatas yang hasilnya adalah 0,077

Dari hasil perhitungan diatas, dapat disimpulkan bahwa $F_{\text {reg }}=76,400 \geq F_{\text {tabel }} 5 \%$ $=3,35$. Dengan demikian hipotesa nihil (Ho yang diajukan ditolak) dan Hipotesa Kerja (Ha) diterima karena $\mathrm{F}_{\text {reg }}$ lebih besar dari $F_{\text {tabel. }}$

Sehingga hipotesa berbunyi "Ada Pengaruh Model Pembelajaran Student Teams Achievement Devision (STAD) dan Problem Solving terhadap Peningkatan Kemampuan Siswa dalam Memahami Sistem Pemerintah Indonesia dalam Pelajaran PKn Kelas X Semester Ganjil 
SMK Telekomunikasi Genteng 2017/2018”. Interprestasi hipotesa kerja mayor dapat dilihat dari perhitungan tabel diatas yang hasilnya adalah 76,400 .

\section{SIMPULAN}

Dari hasil perhitungan statistic minor I dapat disimpulkan bahwa $\mathrm{F}_{\text {reg }}=30,448 \geq$ $\mathrm{F}_{\text {tabel }} 5 \%=3,34$. Dengan demikian dapat dikatakan bahwa "Ada PengaruhModel Pembelajaran Student Teams Achievement Devision (STAD) terhadap Peningkatan Kemampuan Siswa dalam Memahami Sistem Pemerintah Indonesia dalam Pelajaran PKn Kelas X Semester Ganjil SMK Telekomunikasi Genteng 2017/2018”.

Sedangkan hasil dari perhitungan Dari hasil perhitungan minor II diatas, dapat disimpulkan bahwa $\mathrm{F}_{\text {reg }}=0,077 \leq \mathrm{F}_{\text {tabel }} 5 \%$ $=3,34$. Dengan demikian dapat dikatakan bahwa "Tidak Ada pengaruhPembelajaran Problem Solving terhadap Peningkatan Kemampuan Siswa dalam Memahami Sistem Pemerintah Indonesia dalam Pelajaran PKn Kelas X Semester Ganjil SMK Telekomunikasi Genteng 2017/2018”.

Dari hasil perhitungan diatas, dapat disimpulkan bahwa $F_{\text {reg }}=76,400 \geq F_{\text {tabel }} 5 \%$ $=3,35$. Dengan demikian dapat dikatakan bahwa "Ada PengaruhModel Pembelajaran Student Teams Achievement Devision (STAD) dan Problem Solving terhadap Peningkatan Kemampuan Siswa dalam Memahami Sistem Pemerintah Indonesia dalam Pelajaran PKn Kelas X Semester Ganjil SMK Telekomunikasi Genteng 2017/2018”.

\section{DAFTAR PUSTAKA}

Ali, Muhammad. 1996. Penelitian Kependidikan Prosedur Dan Strategi. Bandung: Angkasa.

Anggoro, M. Toha. 2007. Metode

Penelitian. Jakarta: Universitas

Terbuka.

Arikunto,Suharsimi. (2002). Prosedur Penelitian - Suatu Pendekatan Praktek.Jakarta : Rineka Cipta.
Arikunto, Suharsimi. 2003. Prosedur Penelitian, Suatu Praktek. Jakarta:Bina Aksara.

Arikunto, Suharsimi. 2006. Penelitian Tindakan Kelas. Jakarta: PT Rineka Cipta.

Baharuddin, Esa Nur Wahyuni. 2015. Teori Belajar dan Pembelajaran. Yogyakarta: Arruz Media.

Haerhyanto, dkk. 2013. Statistika Pendidikan. Tangerang Selatan: Universitas Terbuka.

Kunandar.2008. Langkah Mudah Penelitian Tindakan Kelas Sebagai

Pengembangan Profesi Guru. Jakarta: PT Raja Grafindo Persada.

Kurniasih, Imas dan Berlin Sani.2015. Ragam Pengembangan Model Pembelajaran. Jakarta: Kata Pena.

Marzuki, 2006.Metodologi Riset Panduan Penelitian, Edisi Kedua. Yogyakarta: Ekosiana.

Moleong, Lexy J. 2000. Metodologi Penelitian Kualitatif. Bandung: PT. Remaja Rosdakarya.

Poerwadarminta.2007. Kamus Umum Bahasa Indonesia. Jakarta: Balai Pustaka.

Sardiman, A. M. 2009. Interaksi dan Motivasi Belajar Mengajar. Jakarta: Rajawali Press.

Sudaryono.2012.Dasar-Dasar Evaluasi Pembelajaran.Yogyakarta: Graha Ilmu

Sugiyono. 2008. Metode Penelitian Kunatitatif Kualitatif dan $R \& D$. Bandung: Alfabeta.

Sugiyono. 2010. Metode Penelitian Kuantitatif, Kualitatif, dan $R \& D$. Bandung: Alfabeta.

Sugiyono. 2012. Metode Penelitian Kunatitatif Kualitatif dan $R \& D$. Bandung: Alfabeta.

Sugiono. 2016. Metode Penelitian Kualitatif, Kuantitatif dan $R \& D$. Bandung: Alfabeta.

Sumiati, Asra. (2008). Metode Pembelajaran. Bandung: Wacana Prima. 
Suprijono, Agus. 2012. Cooperative Learning Teori \& Aplikasi PAIKEM. Yogyakarta: Pustaka Pelajar

Suprijono, Agus. 2009. Cooperative

Learning. Surabaya: Pustaka Pelajar.

Syafi'i, Inu Kencana. 2014. Ilmu

Pemerintahan. Jakarta: Bumi Aksara.

Trianto. 2009.Mendesain Model

Pembelajaran Inovatif-Progresif.

Jakarta Kencana Prenada Group.

Trianto. 2014. Model Pembelajaran

Terpadu: Konsep, Strategi, dan Implementasinya dalam Kurikulum Tingkat Satuan Pendidikan (KTSP). Jakarta. Bumi Aksara.

Widoyoko, Eko Putro. 2013. Teknik Penyusunan Instrumen Penelitian. Yogyakarta: Pustaka Pelajar. 